\title{
OHIO STATE MEETING
}

\section{By F. R. Chapman, D. D. S., Columbus, Ohio, Secretary of the Ohio State Dental Society}

$\mathrm{I}^{\mathrm{n}}$ IS difficult for a $m=m b e r$ to write of the recent meetings of the Ohio State Dental Society without the appearance of boastfulness.

The programs of papers, discussions and clinics were of the highest scientific order ever presented in this state. The papers by Drs. Van Woert, Hartzell and Grieves, with the discussions following, were all that could be expected of men of their attainments.

The address of the President, Dr. Weston A. Price, made report of original investigation along so many various lines of research as to be a course of continuous surprise at the versatility of the speaker.

Of great interest to the audience was the demonstration of an instrument, apparently destined to be of great value to humanity. This wonderful piece of mechanism, a cut of which accompanies this article, is intended for use in hospitals and when properly connected will indicate on a chart the pulse, temperature and respiration of from one to as many patients as may be in the ward, and should any one or more of these factors pass the danger line a light will show or a bell will ring in the nurses' room, superintendent's office or wherever placed.

Dr. Price expressed the desire that this instrument should be given to humanity and the medical profession as a contribution from the dental profession.

An unique feature and one of great interest was the Health and Science Conference at which Dr. Price presided and to which the President, Dr. Homer C. Brown, brought greetings from the National Dental Association.
In succession the audience was addressed by the Hon. Geo. F. Burba, Secretary to the Governor of the states; Dr. Victor C. Vaughn, President-elect of 'the American Medical Association; Dr. E. C. Kirk, Editor of the Dental Cosmos, and Dr. E. F. McCampbell, Secretary of the State Board of Health.

The speaking followed a dinner served in the banquet hall of the Commercial Club of Toledo, the audience overflowing into the corridors.

As honored guests there were present the General Secretary and several Trustees of the National Dental Association, the entire membership of the State Board of Health, the President-elect and the Secretary of the State Medical Association in addition to those appearing on the program.

The clinics, twenty in number, were given by men of nation-wide reputation in the several subjects demonstrated.

The "Progressive" plan allowed each spectator of the large number present ample opportunity to view each clinic without undue crowding.

\section{AFFILIATING WITH NATIONAL IN- CREASES MEMBERSHIP.}

This was the first meeting of our society following affiliation with the National, as a Constituent with our full membership, and some concern had been felt for the possible effect upon the membership of the increased dues.

That such fears were groundless is evidenced by the fact that during the year there were eleven new Component societies organized and fifteen counties added to societies already existing, leaving but two sections yet unorganized, 
and to the further fact that 272 new members have been received.

The Component societies and individuals are showing an increased interest in organization work and organized effort.

\section{AMERICAN MILLER MEMORIAL.}

The committee on the American Miller Memorial reported a balance in the fund of $\$ 4,683.44$ and they were instructed to have the memorial in readiness for dedi- cation at the semi-centennial meeting of this society in 1915 .

It is the earnest wish of this committee that it may be said, on a tablet to be placed on the memorial, that it was erected by contributions from dentists in every state of the Union. Several states have not yet made their donation.

The committees and officers for the year are already at work to maintain, at the next meeting, the high standard set by our late meeting in Toledo.

\title{
THE PROGRESS OF THE CLINIC
}

\author{
By J. V. Conzett, D. D. S., Dubuque, lowa
}

$\mathrm{T}$ HE clinic committee has been organized by the appointment of $\mathrm{J}$. V. Conzett, chairman; Gerald G. Burns, vice-chairman, and A. P. Burkhart secretary; Weston A. Price, chairman of the operative section of the progressive clinic; Thomas P. Hinman, chairman of the crown and bridge section, and $A$. P. Bush, chairman of the miscellaneous section.

The general clinic will be in charge of the following chairmen of the differ$\epsilon$ nt sections:

W. R. Clack-Gold Fillings.

G. W. Dittmar-Gold Inlays.

Edgar M. Carson-Plastic Fillings.

A. W. Starbuck-Porcelain Inlays.

Austin F. James-Pyorrhea.

George H. Wilson-Prosthetics.

H. A. Pullen-Orthodontia.

W. H. De Ford-Anaesthetics and Anaelgesia.

F. B. Moorehead-Surgery.

Marcus L. Ward-Crown and Bridge Work.
The committee has decided to hold two clinics of a half day each upon different days, one a progressive clinic divided into three sections, each one under the chairmanship of a man that has had experience in the conduct of a progressive clinic and will, therefore, be able to give to it the benefit of a previous experience.

It has been the thought of the chairman to place the sections of the general clinic in the hands of men that are especially adapted for the work. How well he has succeeded may be judged by a perusal of the appended list. Each chairman has been given carte blanche in the arrangement of his section, and has been made responsible for its success. In this way we hope to have a clinic that will be an exposition of all that is good in the profession.

Many of the chairmen have aleady their work well under way, and we hope to present the best clinic in the history of the Association. 